\title{
Accelerated versus standard initiation of renal replacement therapy for critically ill patients with acute kidney injury: a systematic review and meta-analysis of RCT studies
}

Heng-Chih Pan ${ }^{1,2,3,4+}$, Ying-Ying Chen ${ }^{2,5+}$, I-Jung Tsai ${ }^{6}$, Chih-Chung Shiao ${ }^{7}$, Tao-Min Huang ${ }^{8}$, Chieh-Kai Chan ${ }^{9}$, Hung-Wei Liao ${ }^{10}$, Tai-Shuan Lai ${ }^{8}, Y_{v}$ vonne Chueh ${ }^{11}$, Vin-Cent Wu ${ }^{8,12^{*}} \odot$ and Yung-Ming Chen ${ }^{2,8}$

\begin{abstract}
Background: Acute kidney injury (AKI) is a common yet possibly fatal complication among critically ill patients in intensive care units (ICU). Although renal replacement therapy (RRT) is an important supportive management for severe AKI patients, the optimal timing of RRT initiation for these patients is still unclear.

Methods: In this systematic review, we searched all relevant randomized controlled trials (RCTs) that directly compared accelerated with standard initiation of RRT from PUBMED, MEDLINE, EMBASE, and Cnki.net published prior to July, 20,2020. We extracted study characteristics and outcomes of being free of dialysis, dialysis dependence and mortality. We rated the certainty of evidence according to Cochrane methods and the GRADE approach.

Results: We identified 56 published relevant studies from 1071 screened abstracts. Ten RCTs with 4753 critically ill AKI patients in intensive care unit (ICU) were included in this meta-analysis. In our study, accelerated and standard RRT group were not associated with all-cause mortality (log odds-ratio [OR]: $-0.04,95 \%$ confidence intervals [CI] -0.16 to $0.07, p=0.46$ ) and free of dialysis ( $\log \mathrm{OR}:-0.03,95 \% \mathrm{Cl}-0.14$ to $0.09, p=0.65)$. In the subgroup analyses, accelerated RRT group was significantly associated with lower risk of all-cause mortality in the surgical ICU and for those who received continuous renal replacement therapy (CRRT). In addition, patients in these two subgroups had higher chances of being eventually dialysis-free. However, accelerated initiation of RRT augmented the risk of dialysis dependence in the subgroups of patients treated with non-CRRT modality and whose Sequential Organ Failure Assessment (SOFA) score were more than 11.

Conclusions: In this meta-analysis, critically ill patients with severe AKI would benefit from accelerated RRT initiation regarding all-cause mortality and being eventually free of dialysis only if they were surgical ICU patients or if they underwent CRRT treatment. However, the risk of dialysis dependence was increased in the accelerated RRT group when those patients used non-CRRT modality or had high SOFA scores. All the literatures reviewed in this study were highly heterogeneous and potentially subject to biases.
\end{abstract}

\footnotetext{
${ }^{*}$ Correspondence: q91421028@ntu.edu.tw

${ }^{\dagger}$ Heng-Chih Pan and Ying-Ying Chen have contributed equally to this paper

${ }^{8}$ Department of Internal Medicine, National Taiwan University Hospital, College of Medicine, National Taiwan University, 7 Chung-Shan South Road, Taipei, Taiwan

Full list of author information is available at the end of the article
} permits use, sharing, adaptation, distribution and reproduction in any medium or format, as long as you give appropriate credit to the original author(s) and the source, provide a link to the Creative Commons licence, and indicate if changes were made. The images or other third party material in this article are included in the article's Creative Commons licence, unless indicated otherwise in a credit line to the material. If material is not included in the article's Creative Commons licence and your intended use is not permitted by statutory regulation or exceeds the permitted use, you will need to obtain permission directly from the copyright holder. To view a copy of this licence, visit http://creativecommons.org/licenses/by/4.0/. The Creative Commons Public Domain Dedication waiver (http://creativeco mmons.org/publicdomain/zero/1.0/) applies to the data made available in this article, unless otherwise stated in a credit line to the data. 
Trial registration CRD42020201466, Sep 07, 2020. https://www.crd.york.ac.uk/prospero/display_record.php?Recor $\mathrm{dID}=201466$.

Keywords: Accelerated dialysis, Dialysis dependence, Free of dialysis, Mortality, Renal replacement therapy, Standard dialysis

\section{Background}

Acute kidney injury (AKI) is common in patients with critical illnesses admitted to intensive care units (ICUs) [1]. The most critical patients with kidney injury may need immediate renal replacement therapy (RRT; dialysis) since AKI is potentially accompanied with lethal complications, such as severe fluid overload, electrolyte disturbances, and acidemia [2]. However, when exactly to initiate RRT in the absence of compellingly lethal complications of AKI in critically ill patients remains unknown [3-5].

The question of whether to utilize accelerated or standard initiation of RRT has been long debated within the past two decades. Previously published related metaanalyses reported potential benefits of accelerated RRT in a subset of patients, but the conclusions have not been widely accepted due to the heterogeneity in the studies and limited number of patients in the randomized controlled trials (RCTs) $[4,6]$. It had previously been concluded that early initialization of dialysis for AKI could be beneficial for surgical patients and in the setting of continuous renal replacement therapy (CRRT) [4]. However, initializing CRRT early has not shown a definitive benefit of patient survival and kidney recovery when compared to intermittent dialysis in other reports $[7,8]$.

Recently, the largest-to-date, multicenter RCT study focusing on this issue has been published, and it recruited patients globally [9]. Therefore, herein, we combined all the available RCT data and conducted a systematic review and meta-analysis to investigate whether accelerated or standard initiation of RRT in critically ill AKI patients is beneficial in terms of several outcomes, including mortality, free of dialysis, dialysis dependence and also scrutinize their subgroup analyses.

\section{Methods}

\section{Search strategy and selection criteria}

We reported the meta-analysis according to the Preferred Reporting Items of Systematic Reviews and MetaAnalyses (PRISMA) statement [10] and used Cochrane methods [11]. We prospectively submitted the systematic review protocol for registration on PROSPERO [CRD42020201466] (Additional file 1: Appendix 6).

\section{Data sources and search strategy}

Electronic searches were performed on PubMed (Ovid), Medline, Embase, Cochrane library, and Cnki.net from inception to July 20, 2020. The search strategies are listed in Additional file 1: Appendix 1. We screened references by titles and abstracts and included related studies for further analysis. Reference lists of related studies, systematic reviews and meta-analyses were manually examined to identify any additional publications relevant to our analysis. Both abstracts and full papers were selected for quality assessment and data syntheses.

\section{Inclusion and exclusion methods}

We enrolled RCT studies with the following inclusion criteria: (1) studies that clearly specified participants were randomized into either control or experiment group; in (2) literature search using $\mathrm{MeSH}$ terms or freetexts words with acute kidney injury, renal replacement therapy, as well as the words characterized with initiation; (3) participants included critical patients with AKI who were at least 18 years of age and were not previously on dialysis; (4) assessed at least one of these outcomes: free of RRT rate, in-hospital mortality, 28-day and 90-day mortality rates after hospital discharge, and dialysis dependence rate after hospital discharge. We excluded articles that did not clearly define the timing of RRT initiations, that included participants younger than 18 years of age, lacked outcomes aforementioned, and participant randomization was not clearly defined. Full-text papers were selected for quality assessment and data syntheses.

\section{Study selection and data extraction}

Two investigators (Ying-Ying Chen and Heng-Chih Pan) independently reviewed the search results and identified eligible studies. Any resulting discrepancies were resolved by discussion with a third investigator (ChihChung Shiao). All relevant data were independently extracted from the included studies by two investigators (Ying-Ying Chen and Heng-Chih Pan) according to a standardized form. Extracted data included study characteristics (leading author, publication year, patient enrollment, sample size, events, duration of follow-up (weeks), the National Clinical Trial number) and participants' baseline (age (years), gender (\%), comorbidities, severity of the illness). When available, odds ratios and 95\% confidence intervals (CIs) from the cohort or case-controlled 
studies were extracted. Other a priori determined parameters were the type of ICU setting (surgical /mixed or medical), criteria used for AKI and severe AKI diagnosis, cohort size, presence of sepsis, study quality, and the proportions of patients on mechanical ventilation. The baseline characteristics of included studies are illustrated in Table 1. The primary outcome was in-hospital mortality rates, while the secondary outcomes were free of RRT and RRT dependence. The survivors who did not need RRT at the end of the study were defined as being free of dialysis; others who were kept on dialysis were considered dialysis dependent. We also evaluated the 28-day and 90-day mortality rates after hospital discharge. Any disagreements were resolved by discussion with the investigator (Vin-Cent Wu).

\section{Quality assessment}

The Cochrane risk of bias tool was used for quality assessment of RCTs [12]. The following domains were assessed: random sequence generation, allocation concealment, blinding of participants and personnel, blinding of outcome assessment, incomplete outcome data, selective reporting and other bias. The criteria for rating study quality were as follows: high risk study (2 or more items rated as high risk of bias); low risk study (5 or more items rated as low risk and no more than one as high risk); moderate risk study (all remaining situations) [13].

\section{Definition}

Accelerated initiation and standard initiation were defined as relatively earlier versus later hemodialysis according to each study. This study was to investigate the effectiveness of earlier rather than later dialysis. Instead of identifying the point in time of early or late dialysis, we have standardized the terminology in this manuscript to refer to all relatively early dialysis timing as accelerated initiation.

\section{Outcomes}

The primary outcome was all-cause mortality. Secondary outcomes were dialysis dependence and being free of RRT rate after hospital discharge.

\section{Subgroup analysis}

We hypothesized that the following factors could have high impact on patient outcomes observed among different studies: patient population (surgical vs. mixed/ medical), disease severity (Sequential Organ Failure Assessment (SOFA) score $\geq 11$ vs. $<11$ ), RRT modality (CRRT vs. intermittent hemodialysis [IHD]/mixed), diabetes mellitus prevalence $(\geq 35 \%$ or $<35 \%)$, discrepancy in interval between accelerated and standard initiation time (difference $\geq 24$ vs. $<24 \mathrm{~h}$ ), using comprehensive AKI definitions (with or without including urine amount criteria), single versus multicenter, and sepsis prevalence.

\section{Data synthesis and statistical analysis}

Overall summary log odds ratios (ORs) and $95 \%$ CIs were calculated by the Mantel-Haenszel method. The fixedeffects model was used to pool the results of the RCTs. Statistical heterogeneity was assessed by the chi-square test and the $I^{2}$ statistic with a $p<0.05$ or $I^{2}>50 \%$ was an indication of substantial heterogeneity. In the case of considerable heterogeneity $\left(I^{2}>50 \%\right.$ or $\left.p<0.05\right)$, we performed a sensitivity analysis to detect the influence of a single study on the overall estimate by omitting one study in turn and pooling the remaining ones. In the subgroup analysis, we performed meta-regression to assess the interaction between variables and the timing of RRT initiation on mortality and RRT dependence. Any potential publication bias was assessed by visual assessment of the funnel plots constructed.

We then did the trial sequential analysis (TSA), as well as the sequential monitoring boundaries. The conventional nonsuperiority boundaries were calculated assuming significance levels of 0.05 , and a power of $80 \%$. The a-spending boundaries were also calculated using significance levels of 0.01 and 0.05 and the O'Brien-Fleming multiple testing procedure [14]. In order to calculate the neutrality zone, we chose a risk ratio reduction of $20 \%$, because of its compatibility with many trials in the ICU [15], and its representation of an absolute mortality difference of around $10 \%$ to $15 \%$, which we considered to be a reasonable effect size. Furthermore, funnel plots were used to evaluate the possibility of publication bias. We used STATA (Version 16, Stata Corp. 2019. College Station, TX: Stata Corp LP) software for the meta-analysis. TSA version 0.9.5.5 (reviewed in November 2016) b software was used for these analyses the cumulative effect of randomized trials on mortality.

\section{Results}

\section{Search results and study characteristics}

The study selection process is summarized in Additional file 1: Figure S1. A total of 25,031 articles were identified through electronic search, and after we excluded duplicate articles and non-relevant articles, the titles and abstracts of the remaining 1071 articles were screened. A total of 56 studies were eligible for full-text reviews, of which 10 RCTs reported data on the timing of RRT initiation; eventually, 4753 critically ill patients with severe AKI were included in our meta-analysis [8, 9, 16-22]. The details of included trials and population characteristics, 


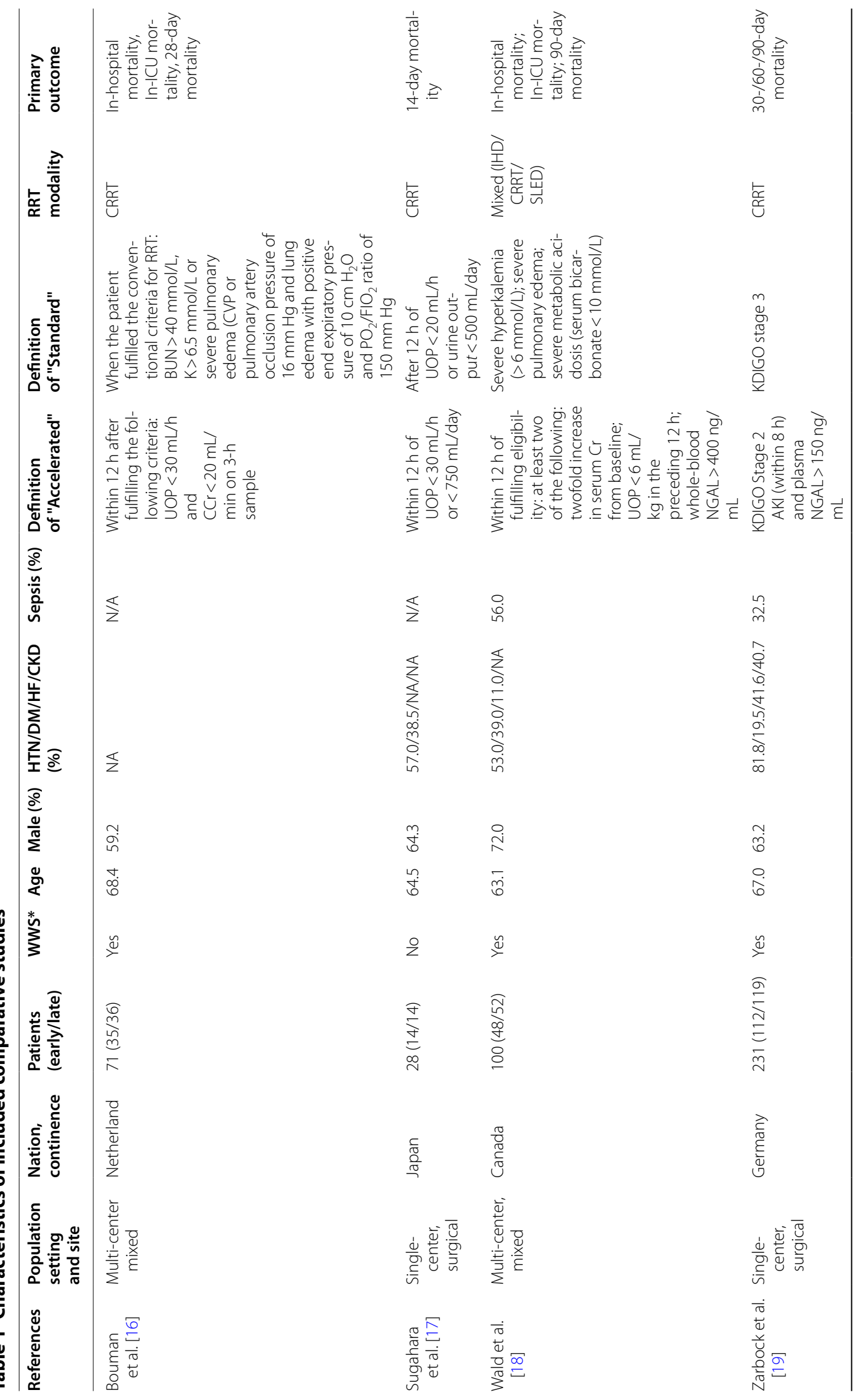




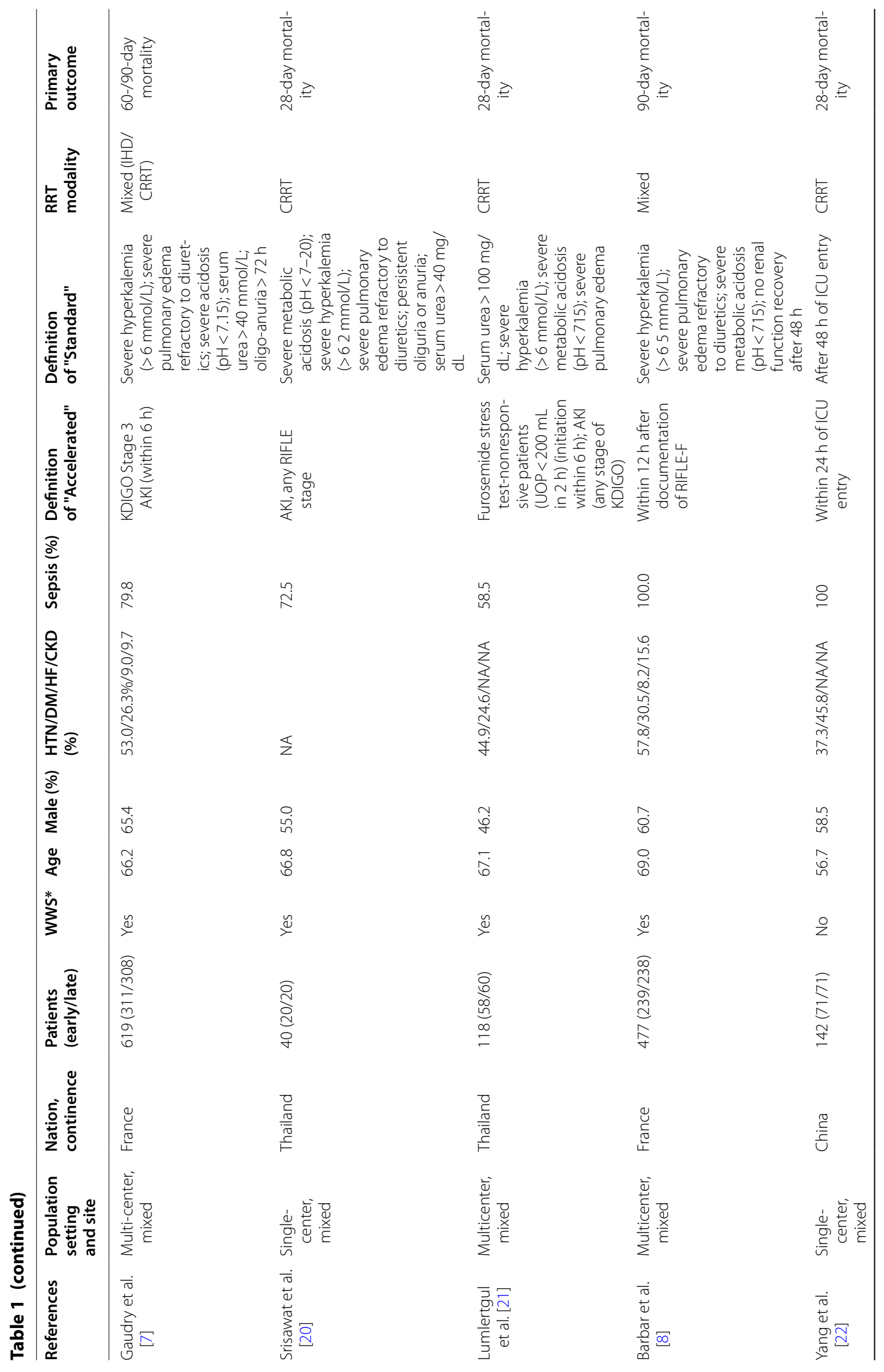




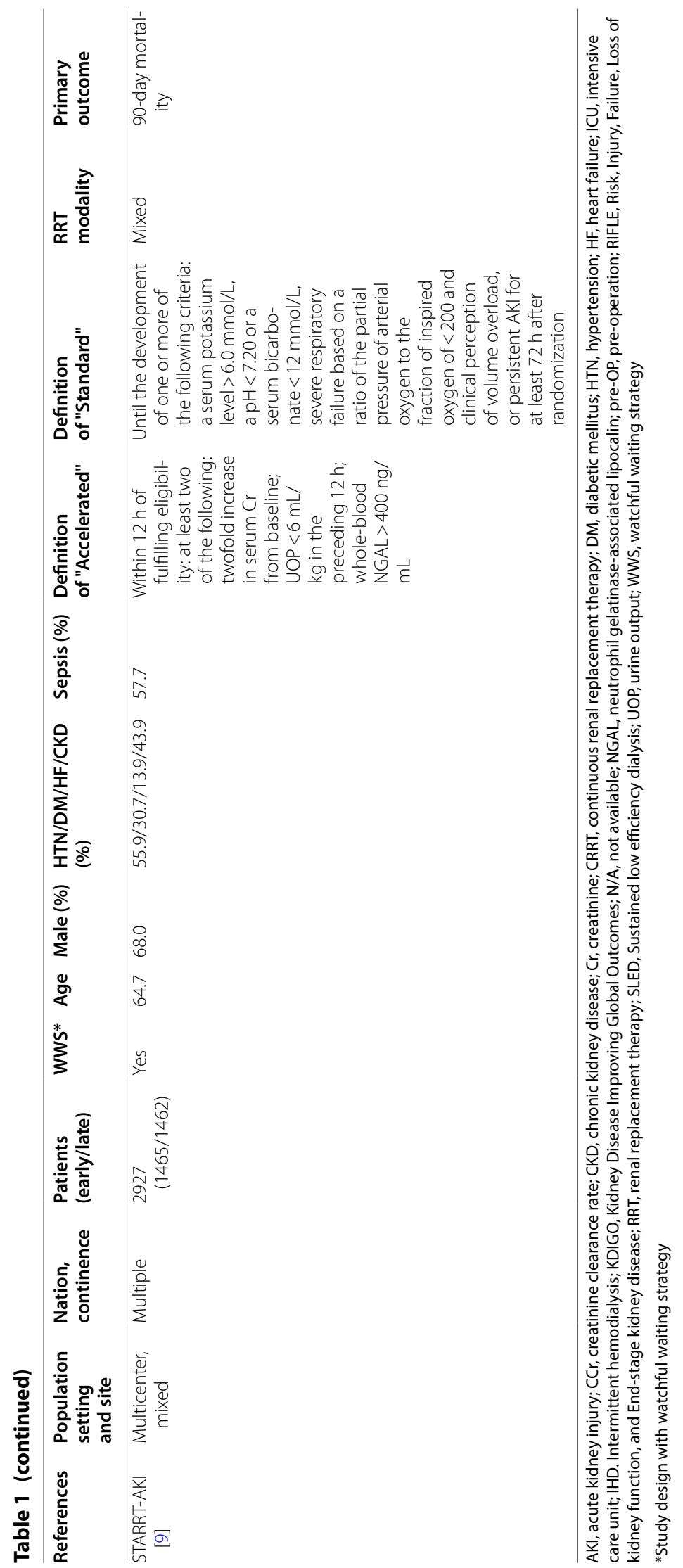


as well as definitions used for accelerated and standard RRT strategies are shown in Table 1. All 10 studies provided quantifiable results for mortality and RRT dependency during the follow-up period. There were two trials that exclusively enrolled surgical patients, of which one of them were entirely from cardiovascular surgery. The remaining 8 studies enrolled patients from mixed surgi$\mathrm{cal} /$ medical ICU setting. Of the 10 studies, six selected CRRT as the only modality for RRT, and the rest were at the discretion of the attending physicians. Of note, one study applied furosemide stress test before randomizing to either accelerated or standard group, and one study chose to use high level of high AKI biomarker (e.g., NGAL) as criteria for receiving randomization $[19,21]$.

\section{Quality of enrolled trials}

The quality of enrolled trials varied, and earlier studies tended to lack sufficient information about participants or personnel blinding and concealment process. The studies were published over 18 years and varied in sample sizes (28-2927 patients). TSA was performed on all RCTs using a significance level of 0.05 ; when the homogeneity of results was considered to be stable, it showed that a total of 8289 patients would be needed to reach a stopping boundary of superiority. However, the Z-curve was parallel to the superior boundary of the accelerated RRT, in term of no superiority to standard RRT and it crossed the neutrality boundary including all trials (Additional file 1: Figure S2).

\section{Publication bias}

The Cochrane Collaboration's tool for assessing the risk of bias revealed that there were low and/or unclear risk in each study in most domain of bias evaluation (Additional file 1: Figure S3).

The risk of bias was low for random sequence generation in 8 trials $(80.0 \%)$; allocation concealment in 8 trials (80.0\%); blinding of outcome assessment in 10 trials (100.0\%); incomplete outcome data in 9 trials $(90.0 \%)$; selective reporting in 8 trials $(80.0 \%)$; and other bias (baseline balance) in 7 trials (70.0\%). Therefore, according to the criteria of overall quality, 8 trials $(80.0 \%)$ were rated as low risk studies, 2 trials $(20.0 \%)$ as moderate, and 0 trial $(0.0 \%)$ as high (Table 2$)$.

Funnel plots were used to evaluate the possibility of publication bias. The results showed generally symmetrical distributions for all-cause mortality, dialysis dependence, and free of dialysis (Additional file 1: Figure S4).

\section{Primary outcomes}

The primary outcome of interest was all-cause mortality, which was based on all trials included and consisted of 4753 patients with 2188 deaths. The pooled mortality rates were $45.5 \%$ (1080 of 2373 ) versus $46.6 \%$ (1108 of $2380)$ in the groups of patients who underwent accelerated versus standard RRT, respectively. No significant survival benefit differences were detected in pooled estimates of included trials between accelerated versus standard RRT group; with a log OR of -0.04 (95\% $\mathrm{CI}-0.16$ to $0.07, p=0.46$ ) (Fig. 1 ). High heterogeneity was found among studies. (Fixed effect model, $I^{2}$ value of $58.71 \%$; random effect model, $I^{2}$ value of $43.49 \%$, Additional file 1: Figure S5) Additionally, there were no significant differences in 28-day and 90-day mortality rates (Additional file 1: Figure S6) between groups with accelerated versus standard initiation of RRT.

\section{Secondary outcomes}

All of the 10 included trials reported the detailed information of free of RRT dependence. In our survey, there were $48.9 \%(1160 / 2380)$ and $49.1 \%(1169 / 2384)$ of severe AKI patients randomized into the accelerated group and standard group, respectively, who did not end up receiving RRT. Among the survivors post discharge, there were $89.7 \%(1160 / 1293)$ and $91.9 \%(1169 / 1272)$ of patients who showed eventual spontaneous renal recovery and did not need long-term RRT in the accelerated group and standard group, respectively. The pooled rates of being free of dialysis showed no statistical significance between accelerated and standard groups with a $\log$ OR of -0.03 $(95 \% \mathrm{CI}-0.14$ to $0.09, p=0.65)$ under fixed effect model $\left(I^{2}\right.$ value $\left.=51.17 \%\right)($ Fig. 2$)$.

The 10 trials included also reported the detailed information of dialysis dependence. Figure 3 shows no significant difference between risk of RRT dependence between accelerated group and standard group $(\log \mathrm{OR}=0.24$, $95 \% \mathrm{CI}-0.03$ to $0.51, p=0.08)$ under fixed effect model with low heterogeneity $\left(I^{2}\right.$ value $\left.=19.82 \%\right)$.

\section{Subgroup analysis}

In our subgroup analyses, the association between accelerated initiation of RRT and a lower risk of all-cause mortality was significant in the setting of surgical ICU patients, CRRT modality and single center settings (Fig. 4). On the other hand, the association between accelerated initiation of RRT and a higher risk of dialysis dependence was also significant in the setting of high disease severity with SOFA score $\geq 11$, mixed RRT modality, lower DM prevalence, interval time between accelerated and standard initiation being less than $24 \mathrm{~h}$, using AKI definitions including urine output and multicenter studies (Additional file 1: Figure S7). We further investigated the possible effect modification of the potential variables for free from dialysis. It was shown that surgical ICU 
Table 2 Summary of included comparative studies for outcome evaluation

\begin{tabular}{|c|c|c|c|c|c|c|c|c|c|}
\hline References & $\begin{array}{l}\text { Population } \\
\text { setting } \\
\text { and site }\end{array}$ & $\begin{array}{l}\text { Nation, } \\
\text { (continence) }\end{array}$ & $\begin{array}{l}\mathrm{HR} / \mathrm{OR} / \\
\mathrm{RR}(\mathrm{Cl}) \\
\text { for primary } \\
\text { endpoint }\end{array}$ & $\begin{array}{l}\text { Urine } \\
\text { output } \\
\text { (mL/24 h) }\end{array}$ & $\begin{array}{l}\text { AKI } \\
\text { definition } \\
\text { by stage }\end{array}$ & $\begin{array}{l}\text { Large } \\
\text { population } \\
\text { (sample } \geq 100)\end{array}$ & $\begin{array}{l}\text { Time } \\
\text { difference } \\
\text { between early } \\
\text { and late (hour) }\end{array}$ & $\begin{array}{l}\text { Study } \\
\text { quality }\end{array}$ & SOFA score \\
\hline $\begin{array}{l}\text { Bouman } \\
\text { et al. [16] }\end{array}$ & $\begin{array}{l}\text { Multicenter } \\
\text { mixed }\end{array}$ & $\begin{array}{l}\text { Netherland } \\
\text { (Europe) }\end{array}$ & NA & NA & NA & Small & 34.8 & High & 10.36 \\
\hline $\begin{array}{l}\text { Sugahara } \\
\text { et al. [17] }\end{array}$ & $\begin{array}{l}\text { Single- } \\
\text { center, } \\
\text { surgical }\end{array}$ & Japan (Asia) & NA & NA & NA & Small & 2.4 & Moderate & NA \\
\hline $\begin{array}{l}\text { Wald et al. } \\
\text { [18] }\end{array}$ & $\begin{array}{l}\text { Multicenter, } \\
\text { mixed }\end{array}$ & $\begin{array}{l}\text { Canada } \\
\text { (North } \\
\text { America) }\end{array}$ & NA & 329.8 & NA & Large & 24 & High & 12.62 \\
\hline $\begin{array}{l}\text { Zarbock } \\
\text { et al. [19] }\end{array}$ & $\begin{array}{l}\text { Single- } \\
\text { center, } \\
\text { surgical }\end{array}$ & $\begin{array}{l}\text { Germany } \\
\text { (Europe) }\end{array}$ & $\begin{array}{r}0.66(0.45- \\
0.97) /-/-\end{array}$ & 358.7 & $\begin{array}{l}\mathrm{KDIGO} \\
\text { Stage } 2\end{array}$ & Large & 20 & High & 15.81 \\
\hline $\begin{array}{l}\text { Gaudry et al. } \\
\text { [7] }\end{array}$ & $\begin{array}{l}\text { Multicenter, } \\
\text { mixed }\end{array}$ & $\begin{array}{l}\text { France } \\
\text { (Europe) }\end{array}$ & $\begin{array}{c}{ }^{*} 1.02(0.81- \\
1.29) /-/-\end{array}$ & NA & $\begin{array}{l}\text { KDIGO } \\
\text { Stage } 3\end{array}$ & Large & 55 & High & 10.85 \\
\hline $\begin{array}{l}\text { Srisawat } \\
\text { et al. [20] }\end{array}$ & $\begin{array}{l}\text { Single- } \\
\text { center, } \\
\text { mixed }\end{array}$ & $\begin{array}{l}\text { Thailand } \\
\text { (Asia) }\end{array}$ & NA & NA & RIFLE-R & Small & 48 & High & 9.28 \\
\hline $\begin{array}{l}\text { Lumlertgul } \\
\text { et al. [21] }\end{array}$ & $\begin{array}{l}\text { Multicenter, } \\
\text { mixed }\end{array}$ & $\begin{array}{l}\text { Thailand } \\
\text { (Asia) }\end{array}$ & $\begin{array}{r}0.96(0.60- \\
1.53) /-/-\end{array}$ & 551.1 & $\begin{array}{l}\text { KDIGO } \\
\text { Stage } 1\end{array}$ & Large & 19 & High & 12.04 \\
\hline $\begin{array}{l}\text { Barbar et al. } \\
\text { [8] }\end{array}$ & $\begin{array}{l}\text { Multicenter, } \\
\text { mixed }\end{array}$ & $\begin{array}{l}\text { France } \\
\text { (Europe) }\end{array}$ & NA & NA & RIFLE-F & Large & 45 & High & 12.3 \\
\hline $\begin{array}{l}\text { Yang et al. } \\
\text { [22] }\end{array}$ & $\begin{array}{l}\text { Single- } \\
\text { center, } \\
\text { mixed }\end{array}$ & China (Asia) & NA & 498.9 & NA & Large & NA & Moderate & 7.35 \\
\hline $\begin{array}{l}\text { STARRT-AKI } \\
\text { [9] }\end{array}$ & $\begin{array}{l}\text { Multicenter, } \\
\text { mixed }\end{array}$ & $\begin{array}{l}\text { Multiple } \\
\text { countries } \\
\text { (Asia, } \\
\text { Europe, } \\
\text { North } \\
\text { America, } \\
\text { Oceania, } \\
\text { South } \\
\text { America) }\end{array}$ & $\begin{array}{l}-/^{*} 1.05 \\
\quad(0.90- \\
1.23) / 1.00 \\
(0.93- \\
1.09)\end{array}$ & 464 & $\begin{array}{l}\text { KDIGO } \\
\text { Stage } 2\end{array}$ & Large & NA & High & 11.7 \\
\hline
\end{tabular}

AKI, acute kidney injury; HR, hazard ratio; KDIGO, Kidney Disease Improving Global Outcome; NA, not available; OR, odds ratio; RIFLE, Risk, Injury, Failure, Loss of kidney function, and End-stage kidney disease RR, relative risk; SOFA, Sequential Organ Failure Assessment

${ }^{*}$ Adjusted

patients, using CRRT modality, high DM prevalence and single center settings also played positive associations between accelerated initiation of RRT strategy and higher chance of being free of dialysis (Fig. 5).

\section{Sensitivity analysis}

Different models were used to evaluate the primary and secondary outcomes. There were no significant differences in all cause-mortality, dialysis dependence and free of dialysis between accelerated and standard groups in the pooled data of the 10 studies in random effects model (Additional file 1: Figures S5, S8, S9). In five RCTs that provided the adjusted hazard ratio (HR) in regard to patient mortality, the risk of all-cause mortality in accelerated RRT was similar to that of standard RRT (adjusted $\mathrm{HR}=1.02$, 95\% CI 0.94-1.09, $p<0.01$, Additional file 1: Figure S10).
Among the 10 RCTs, the definition of accelerated/early and standard/delayed initiation of RRT of the study by Gaudry was quite different from that of other RCTs, and the study by Yang was not a SCI (science citation index) article. After excluding the two studies, the pooled data of the remaining $8 \mathrm{RCTs}$ revealed similar results in primary and secondary outcomes (Additional file 1: Figures S11S13). Consistent with our main results, the critically ill AKI patients could benefit from accelerated RRT regarding all-cause mortality and free of dialysis only if they were surgical ICU patients or underwent CRRT treatment. The findings were not materially different from the standard analysis and remained robust in the sensitivity analyses. Additionally, the sensitivity analysis revealed that the results were not altered when removing anyone study (data not shown). 


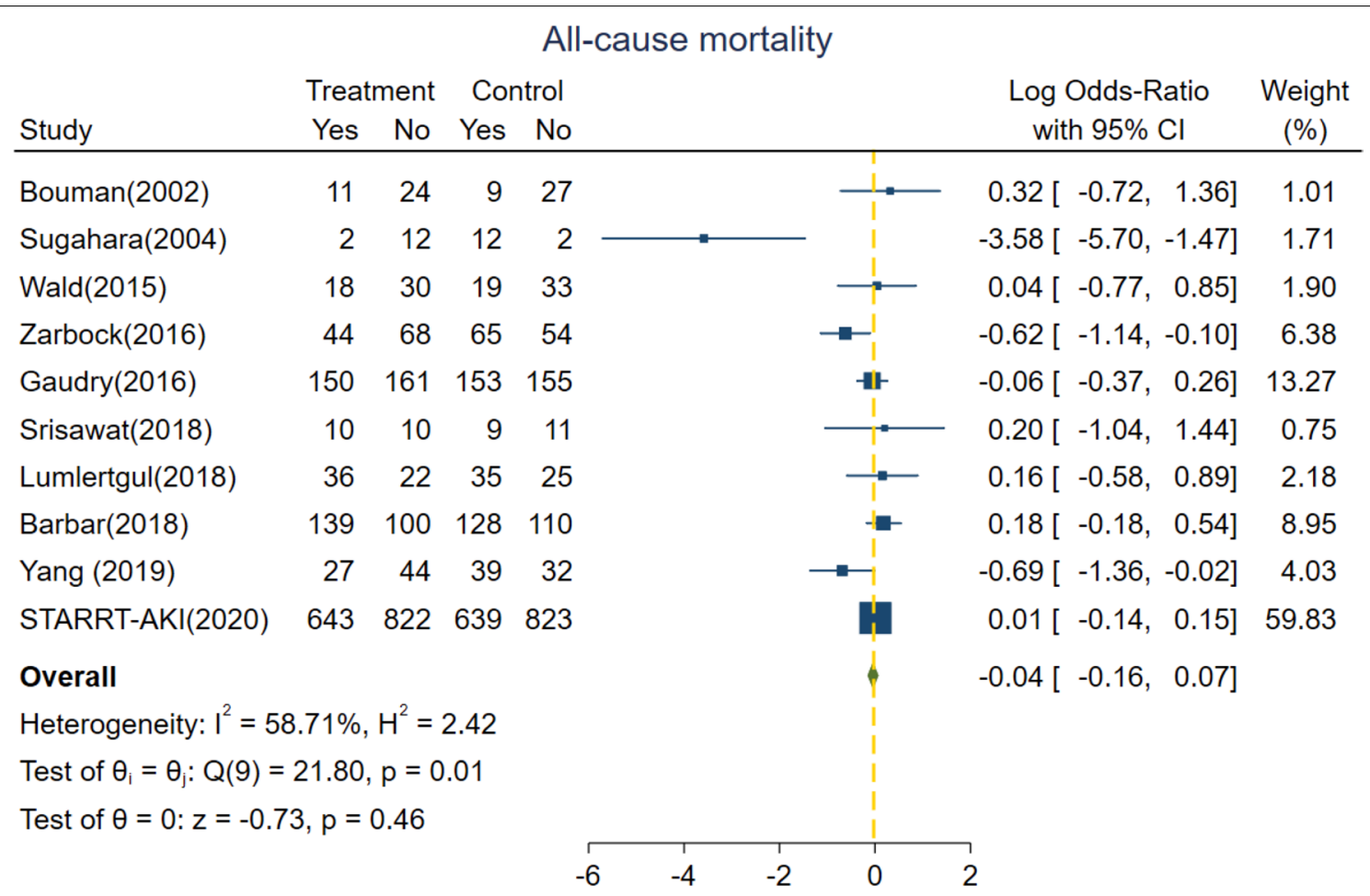

Fixed-effects Mantel-Haenszel model

Fig. 1 Forest plot for all-cause mortality comparing accelerated versus standard initiation of RRT among RCTs. RCT, randomized controlled trials; RRT, renal replacement therapy

Assessment of evidence quality and summary of findings. Evidence quality assessment was performed using the GRADE system (Additional file 1: Appendix 7). We evaluated the primary outcome and secondary outcomes and presented as a summary of findings in supplementary file.

\section{Discussion}

In a systematic review of 10 RCTs including 4753 critically ill patients with severe AKI, we did not find significant survival benefits (28-day nor 90-day mortality) in patients who underwent accelerated versus standard RRT. For those critical AKI patients who underwent CRRT treatment or were in the surgical ICU setting, accelerated RRT showed survival benefits as well as more free of dialysis. However, the relative risk of dialysis dependence increased in accelerated RRT group, when those AKI patients were non-CRRT and of high disease severity groups. To our knowledge, this is the most comprehensive systematic review to date that included the highest number of RCTs and the largest number of critically ill AKI patients.

Even though the literatures addressing this comparison were highly heterogeneous, our funnel meta-regression analysis showed only limited publication bias. Our TSA showed a constant result and low risk of bias among these randomized studies comparing the impact on mortality between accelerated versus standard initiation of dialysis in critically ill AKI patients. Furthermore, the total number of patients is enough to achieve a confident conclusion because the Z-curve did cross the neutrality line from the TSA.

\section{Being free of dialysis}

Contrary to the previous reports, we did not find a significant effect of standard dialysis leading to a higher rate of being free of RRT when all patient populations were considered; however, in critically ill AKI patients with higher disease severity or who underwent CRRT treatment, there were higher rates of being free of dialysis among the survivors.

Some large observational studies, that only included patients who were receiving RRT, suggest that CRRT is an independent predictor of renal recovery among survivors [23, 24]. CRRT could permit slow but continuous removal of solutes and water, thereby conferring better hemodynamic tolerability. Relative hemodynamic stability during CRRT sessions, compared to intermittent dialysis, could mitigate occult kidney injury. We showed the evidence to elucidate the impact of choice of therapy on this outcome from RCTs [25]. 


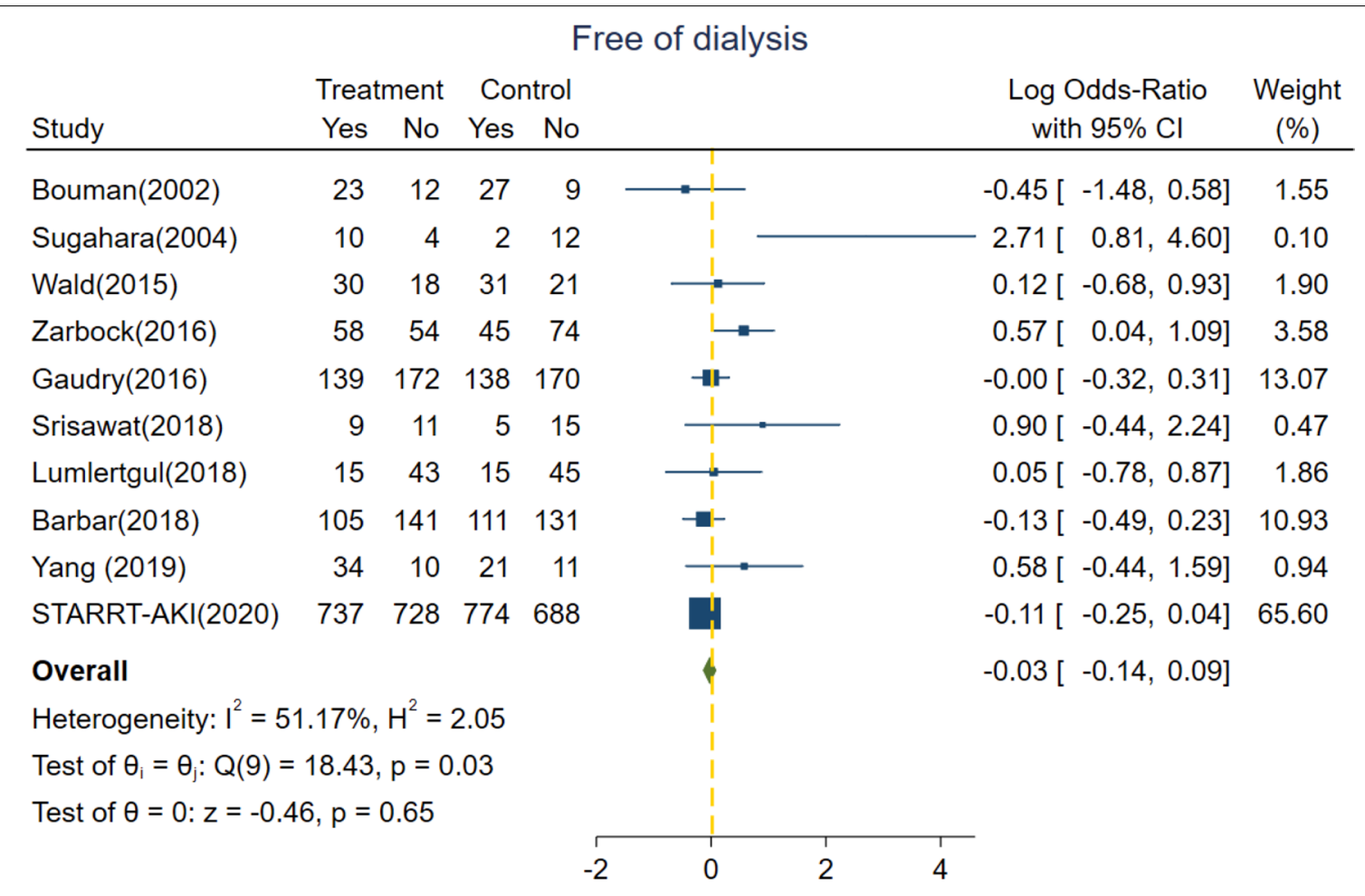

Fixed-effects Mantel-Haenszel model

Fig. 2 Forest plot for dialysis dependence comparing accelerated versus standard initiation of RRT among RCTs. RCT, randomized controlled trials; RRT, renal replacement therapy

\section{Dialysis dependence}

Another conclusion to result from this meta-analysis is that about $90.8 \%$ (89.7\% in accelerated and $91.9 \%$ in standard group) of the survivors with severe AKI in our survey did not undergo dialysis at the end of the studies, due to the fortunate spontaneous recovery of renal function from managing underlying etiologies and/or accompanying co-morbidities which occurred within hours to days.

To our knowledge, our study is the largest systematic review to date to address the question of optimal timing regarding RRT initiation and its impact on patient survival and dialysis dependence that included several recent elegant large RCTs [7-9, 19]. Furthermore, our finding is consistent in $73.3 \%$ of RCTs when watchful waiting strategy was adopted into the study design. For the sake of all-cause mortality, it is startling to find $90.8 \%$ of the survivors to avoid the potential risks of an extracorporeal support technique if they do not actually need it, not to mention the savings to be yielded in terms of medical cost, time, man-power and capacity of the ICU.

A delayed strategy for the initiation of RRT could allow time for stabilization of the patients' condition, thus enabling starting of RRT when the patients were more hemodynamically stable, or even precluding the need for such therapy if the renal function recovers spontaneously that contributed to free of dialysis. The results of the BICAR-ICU study [26] suggested that optimizing medical treatment can avoid RRT for severely metabolically acidotic AKI cases, and thus reducing mortality. Moreover, the time needed for most inotropes to reach their efficacy is less than $28.1 \mathrm{~h}$, which is the average difference in timing between these accelerated versus standard initiation. This implicated that the patients who would have to utilize RRTs were at a more hemodynamically stable state. Although we still lack miracle drug therapies capable of blocking or reversing severe AKI, accelerated RRT might not be the solution to all critical AKI patients.

\section{Subgroup analyses}

Previous investigation had looked at special populations such as sepsis and found no significant difference in survival of AKI patients according to strategy for the initiation of RRT [27]. In the current study, we further tried to explore the clinical impact of some other potential factors, such as different study settings, disease severities, diabetic percentage, and dialysis discrepancy time less than $24 \mathrm{~h}$. In our subgroup analyses, we found no survival 


\begin{tabular}{|c|c|c|c|c|c|c|c|}
\hline \multirow[b]{3}{*}{ Study } & \multicolumn{6}{|c|}{ Dialysis Dependence } & \multirow{3}{*}{$\begin{array}{c}\text { Weight } \\
(\%)\end{array}$} \\
\hline & \multicolumn{2}{|c|}{ Treatment } & \multicolumn{2}{|c|}{ Control } & & \multirow{2}{*}{$\begin{array}{c}\text { Log Odds-Ratio } \\
\text { with } 95 \% \mathrm{Cl}\end{array}$} & \\
\hline & Yes & No & Yes & No & & & \\
\hline Bouman(2002) & 1 & 24 & 0 & 27 & & $1.21[-2.03,4.46]$ & 0.47 \\
\hline Sugahara(2004) & 2 & 12 & 0 & 2 & & $0.00[-3.33,3.33]$ & 0.73 \\
\hline Wald(2015) & 0 & 48 & 2 & 52 & & $-1.53[-4.59,1.53]$ & 2.44 \\
\hline Zarbock(2016) & 9 & 67 & 8 & 53 & $\rightarrow-$ & $-0.12[-1.13,0.90]$ & 8.17 \\
\hline Gaudry(2016) & 22 & 179 & 17 & 178 & $-\square$ & $0.25[-0.41,0.92]$ & 16.05 \\
\hline Srisawat(2018) & 1 & 10 & 6 & 11 & $\frac{1}{1}$ & $-1.70[-3.98,0.59]$ & 4.48 \\
\hline Lumlertgul(2018) & 7 & 22 & 10 & 25 & $\rightarrow-$ & $-0.23[-1.35,0.89]$ & 7.18 \\
\hline Barbar(2018) & 2 & 101 & 3 & 110 & $\longrightarrow$ & $-0.32[-2.13,1.49]$ & 2.93 \\
\hline Yang (2019) & 10 & 34 & 11 & 21 & $\rightarrow$ & $-0.58[-1.59,0.44]$ & 10.28 \\
\hline STARRT-AKI(2020) & 85 & 814 & 49 & 815 & L & $0.55[0.19,0.92]$ & 47.27 \\
\hline Overall & & & & & $\bullet$ & $0.24[-0.03,0.51]$ & \\
\hline Heterogeneity: $I^{2}=1$ & $9.82 \%$, & $\mathrm{H}^{2}=$ & 1.25 & & I & & \\
\hline Test of $\theta_{\mathrm{i}}=\theta_{\mathrm{j}}: \mathrm{Q}(9)=$ & 11.22, & $p=0$ & & & 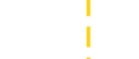 & & \\
\hline Test of $\theta=0: z=1.7$ & $p=0$ & .08 & & & & & \\
\hline & & & & -5 & 0 & 5 & \\
\hline
\end{tabular}

Fixed-effects Mantel-Haenszel model

Fig. 3 Forest plot for free of dialysis comparing accelerated versus standard initiation of RRT among RCTs. RCT, randomized controlled trials; RRT, renal replacement therapy

differences between accelerated versus standard RRT initiation time even after multivariate adjustment. We also found that the values of combining serum creatinine and urine output (which are components of the modern RIFLE and KDIGO criteria), as well as percentages of the septic patients had no significant impact on patient outcomes, and therefore they should not be used to decide on the time of RRT initiation.

There are some possible explanations for the discordance and heterogeneity among different studies. Using varying AKI definitions and different AKI stage criteria for RRT initiation could account for part of the observed heterogeneities. For most of the previously reported cohort studies, the differences in pre-intervention study groups contributed to the heterogeneity of the results, and therefore made the systematic reviews difficult to interpret.

\section{Strengths and limitations}

The strength of our present analysis rests on our extensive literature search on related RCTs. We used standard Cochrane protocols and had the largest cumulative RCTs study sample size to date in comparison with the previous reports. We only focused on the RCTs that had a reasonable quality with limited differential dropout based on the assigned treatment arm. One of the differences that our study has in comparison with previous reports is the inclusion of the recently published elegant RCT studies with large patient numbers and global multi-national inclusion in patients' recruiting [9], especially its effect on free of dialysis. These recently published RCTs that included watchful waiting strategies were not included in prior meta-analysis; this accounts for the differences in our results from those of earlier authors [28-31]. The strength of our meta-analysis also lies in comprehensive data search with subgroup analyses across several clinical scenarios. We adapted the GRADE approach to rate the certainty of evidence [32].

Protocolizing the optimal timing of RRT for all AKI patients may be too crude and imprecise, in the era of modern personalized medicine. It could be more important to give clinicians reliable information about when to initialize RRT in certain precisely defined patient groups. The negative result on the primary endpoint turns out to be hiding among a high level of heterogeneity in terms of disease progression, that could not be accurately predicted by the staging of AKI at the time of inclusion. 


\section{All-cause of mortality}

Subgroup
Surgery
Surgery (2)
Mixed/Medical (8)
SOFA
Low SOFA (4)
High SOFA (5)
CRRT
CRRT (6)
Non-CRRT (4)
DM
Low prevalence DM (5)
High prevalence DM (4)
TD
TD <24h (5)
TD >= 24h (5)
UO
AKI with UO (9)
AKI wihout UO(1)
Center
Single center (4)
Multi-center (6)
Sepsis
All sepsis (1)
Nonspecific causes (7)

\section{$\log$ OR $[95 \% \mathrm{CI}]$}

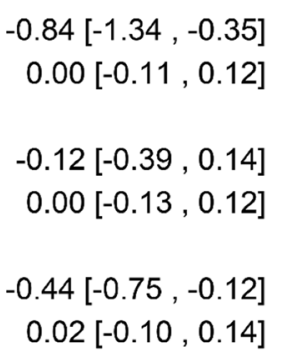

$-0.01[-0.13,0.11]$

$-0.52[-0.97,-0.08]$

$-0.05[-0.19,0.09]$

$-0.03[-0.24,0.19]$

$-0.02[-0.14,0.09]$

$-0.69[-1.36,-0.02]$

$-0.70[-1.07,-0.32]$

$0.03[-0.09,0.15]$

$0.18[-0.18,0.54]$

$-0.05[-0.18,0.07]$
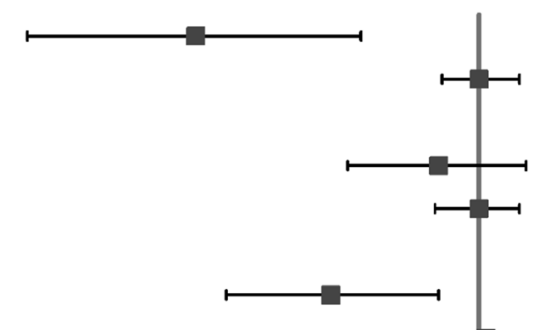

$$
-1.5
$$
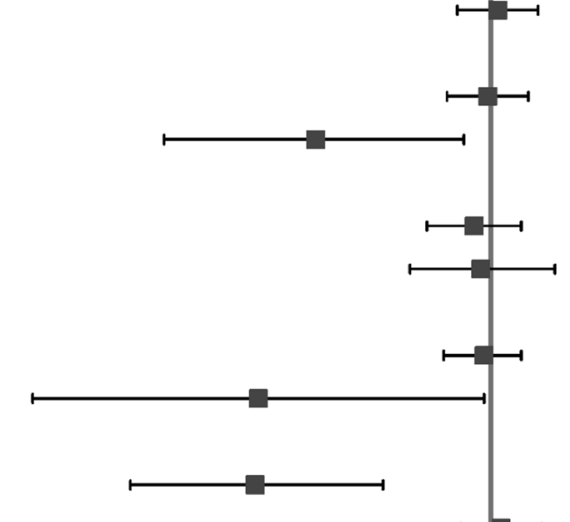

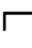

Fig. 4 Forest plots of subgroups for all-cause mortality comparing accelerated versus standard initiation of RRT among RCTs. RCT, randomized controlled trials; RRT, renal replacement therapy

In our systematic review, we found no further information regarding the other factors associated with mortality, and therefore, we cannot comment on differences in the outcomes on the basis of one single intervention, i.e., accelerated or standard dialysis initiation. There were only two trials that exclusively enrolled surgical patients, of which one of them were entirely from cardiovascular surgery. Furthermore, no trial standardized the dialysis modality or dose delivered during initializing RRT. We were not able to access the unpublished reports, e.g., negative results of accelerated RRT which might have biased our results. Although our funnel meta-regression and Cochrane Collaboration's tool analysis showed a limited publication bias (supplementary figures), the bias is always difficult to ascertain with a small sample size of the included studies. Finally, the definition of "accelerated" RRT was variable and may have unduly influenced pooled effect estimates. The timing of RRT defined by traditional markers was relatively late which may influence the effectiveness of the early treatment. In our TSA, we included trials of patients without severe AKI, which yielded enough information size to conclude that accelerated RRT probably does not benefit patients (due to the $Z$ curve crossing the neutrality line). Nonetheless, our conclusion yielded from studies that consisted of different study designs and different clinical scenarios. Of note, we just raised the possibility of the timing of RRT defined by traditional markers was relatively late, which may influence the effectiveness of the early treatment. Our intention was to investigate whether receiving RRT earlier than the traditional timing would influence its effectiveness. Further research efforts are certainly needed for the pursuit of better precision medicine. It could be more fruitful to investigate if different etiologies of AKI (pre-renal vs. renal vs. obstructive, cardiogenic shock, hypovolemic shock, sepsis-related, etc.) affect outcomes of accelerated versus standard RRT; and to evaluate if the efficacy of CRRT fits into various underlying 


\section{Free of dialysis}

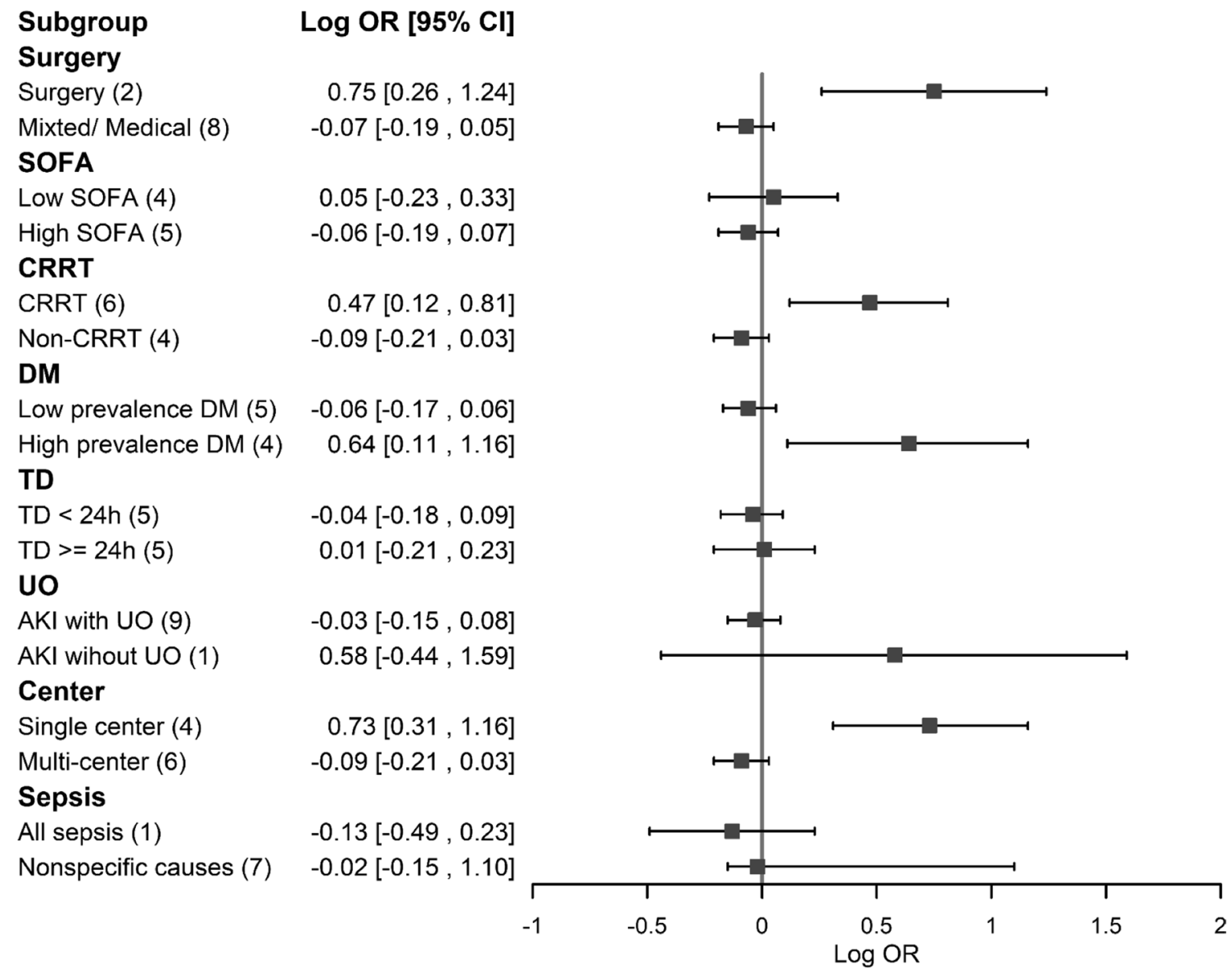

Fig. 5 Forest plots of subgroups for free of dialysis comparing accelerated versus standard initiation of RRT among RCTs. RCT, randomized controlled trials; RRT, renal replacement therapy

causes of AKI in critically ill patients. These issues can be incorporated into the design of future RCTs in evaluating the optimal timing and modalities of RRT for critically ill AKI patients, in order to reach a new horizon and higher success rate of treatment in this field. Moreover, further investigations into improvement in treatments to resuscitate the patients' hemodynamic stability and to manage each underlying mechanisms of AKI might contribute to mitigate the current extremely high mortality rate of these critically ill patients with RRT-requiring AKI.

\section{Conclusion}

Accelerated dialysis initiation in critically ill patients with severe AKI does not decrease mortality, alter the possibility from free of dialysis, or mitigate dialysis dependence among survivors as compared with the standard RRT initiation strategy. However, in patients who underwent CRRT treatment or were in the surgical ICU setting, accelerated RRT could benefit the possibility of survival and free of dialysis. However, accelerated RRT initiation could be associated with higher risk of dialysis dependence when those severe AKI patients were treated with non-CRRT modality or were of high disease severity.

\section{Supplementary information}

The online version contains supplementary material available at https://doi. org/10.1186/s13054-020-03434-z.

Additional file 1: Supplementary appendix.

\section{Abbreviations}

AKI: Acute kidney injury; Cl: Confidence intervals; CRRT: Continuous renal replacement therapy; DM: Diabetes mellitus; FST: Furosemide stress test (FST); ICU: Intensive care units; IHD: Intermittent hemodialysis (IHD); OR: Odds-ratio; PRISMA: Preferred Reporting Items of Systematic Reviews and Meta-Analyses; RCTs: Randomized controlled trials; RRT: Renal replacement therapy; TSA: Trial sequential analysis; WWS: Watchful waiting strategy. 


\section{Acknowledgements}

The authors would like to thank the staff of the Second Core Lab in the Department of Medical Research in National Taiwan University Hospital for technical assistance. The authors thank Dr. Jeff Chueh of Glickman Urology and Kidney Institute, Cleveland Clinic, Cleveland, $\mathrm{OH}$, USA, for his critical comments.

\section{Authors' contributions}

VCW chaired the group, conceived and designed the study, performed statistical analysis and contributed to data collection, data interpretation, and critical revision of the manuscript. YYC and HCP conducted a literature search, statistical analysis and wrote the manuscript. CCS performed a literature search, wrote the manuscript, and performed a critical revision of the manuscript. $\mathrm{TMH}, \mathrm{CKC}$, and HWL performed literature search and summary. TSL, YC, YMC and VCW wrote the manuscript and performed a critical review of the manuscript. All authors contributed to subsequent drafts and examined the paper. All authors read and approved the final manuscript.

\section{Funding}

This study was supported by Taiwan National Science Council

[104-2314-B-002-125-MY3, 106-2314-B-002 -166 -MY3,107-2314-B-002-

026-MY3], National Health Research Institutes [PH-102-SP-09)], National Taiwan University Hospital [106-FTN20, 106-P02, UN106-014, 106-S3582, 107-S3809, 107-T02,PC1246,VN109-09,109-S4634,UN109-041 ] and Ministry of Science and Technology (MOST) of the Republic of China (Taiwan) [grant number, MOST 106-2321-B-182-002, MOST 107-2321-B-182-004, MOST 108-2321-B182-003, MOST 109-2321-B-182-001].

\section{Availability of data and materials}

The datasets used and/or analyzed during the current study are available from the corresponding author on reasonable request.

\section{Ethics approval and consent to participate} Not applicable.

\section{Consent for publication}

Not applicable.

\section{Competing interests}

The authors declare that they have no competing interests.

\begin{abstract}
Author details
${ }^{1}$ Division of Nephrology, Department of Internal Medicine, Keelung Chang Gung Memorial Hospital, Keelung, Taiwan. ${ }^{2}$ Graduate Institute of Clinical Medicine, College of Medicine, National Taiwan University, Taipei, Taiwan. ${ }^{3}$ Chang Gung University College of Medicine, Taoyuan, Taiwan. ${ }^{4}$ Community Medicine Research Center, Keelung Chang Gung Memorial Hospital, Keelung, Taiwan. ${ }^{5}$ Division of Nephrology, Department of Internal Medicine, MacKay Memorial Hospital, Taipei, Taiwan. ${ }^{6}$ Division of Nephrology, Department of Pediatrics, National Taiwan University Children's Hospital, Taipei, Taiwan. ${ }^{7}$ Division of Nephrology, Department of Internal Medicine, Saint Mary's Hospital Luodong, Yilan, Taiwan. ${ }^{8}$ Department of Internal Medicine, National Taiwan University Hospital, College of Medicine, National Taiwan University, 7 Chung-Shan South Road, Taipei, Taiwan. ${ }^{9}$ Department of Internal Medicine, National Taiwan University Hospital, Hsin-Chu Branch, Hsin Chu County, Taiwan. ${ }^{10}$ Chinru Clinic, Taipei, Taiwan. ${ }^{11}$ Department of Family Medicine, Cleveland Clinic Akron General Hospital, Akron, OH, USA. ${ }^{12}$ National Taiwan University Hospital Study Group of ARF (NSARF), Taiwan Consortium for Acute Kidney Injury and Renal Diseases (CAKS, TCTC), Taipei, Taiwan.
\end{abstract}

Received: 1 October 2020 Accepted: 11 December 2020 Published online: 05 January 2021

\section{References}

1. Hoste EA, Bagshaw SM, Bellomo R, Cely CM, Colman R, Cruz DN, Edipidis K, Forni LG, Gomersall CD, Govil D, et al. Epidemiology of acute kidney injury in critically ill patients: the multinational AKI-EPI study. Intensive Care Med. 2015;41(8):1411-23.
2. Shiao CC, Wu VC, Li WY, Lin YF, Hu FC, Young GH, Kuo CC, Kao TW, Huang DM, Chen YM, et al. Late initiation of renal replacement therapy is associated with worse outcomes in acute kidney injury after major abdominal surgery. Crit Care. 2009;13(5):R171.

3. Shiao CC, Huang TM, Spapen HD, Honore PM, Wu VC. Optimal timing of renal replacement therapy initiation in acute kidney injury: the elephant felt by the blindmen? Crit Care. 2017;21(1):146.

4. Lai TS, Shiao CC, Wang JJ, Huang CT, Wu PC, Chueh E, Chueh SJ, Kashani K, Wu VC. Earlier versus later initiation of renal replacement therapy among critically ill patients with acute kidney injury: a systematic review and meta-analysis of randomized controlled trials. Ann Intensive Care. 2017;7(1):38.

5. Chen KH, Doi K, Wu VC, Chu TS, Shiao CC. Nsarf: Using "temporal parameters" to define the timing of renal replacement therapy in acute kidney injury? There are other better choices. Nephrology (Carlton). 2018;23(5):385-8.

6. Gaudry S, Hajage D, Benichou N, Chaïbi K, Barbar S, Zarbock A, Lumlertgul N, Wald R, Bagshaw SM, Srisawat N. Delayed versus early initiation of renal replacement therapy for severe acute kidney injury: a systematic review and individual patient data meta-analysis of randomised clinical trials. Lancet. 2020;395:1506-15.

7. Gaudry S, Hajage D, Schortgen F, Martin-Lefevre L, Pons B, Boulet E, Boyer A, Chevrel G, Lerolle N, Carpentier D, et al. Initiation strategies for renal-replacement therapy in the intensive care unit. N Engl J Med. 2016;375(2):122-33

8. Barbar SD, Clere-Jehl R, Bourredjem A, Hernu R, Montini F, Bruyere R, Lebert C, Bohe J, Badie J, Eraldi JP, et al. Timing of renal-replacement therapy in patients with acute kidney injury and sepsis. N Engl J Med. 2018;379(15):1431-42.

9. Bagshaw SM, Wald R, Adhikari NKJ, Bellomo R, da Costa BR, Dreyfuss D, STARRT-AKI Investigators, Canadian Critical Care Trials Group tA, New Zealand Intensive Care Society Clinical Trials Group tUKCCRGtCNTN, the Irish Critical Care Trials G, et al. Timing of initiation of renal-replacement therapy in acute kidney injury. N Engl J Med. 2020;383(3):240-51.

10. Higgins JP, Altman DG, Gotzsche PC, Juni P, Moher D, Oxman AD, Savovic J, Schulz KF, Weeks L, Sterne JA. The Cochrane Collaboration's tool for assessing risk of bias in randomised trials. BMJ (Clin Res Ed). 2011;343:d5928.

11. Salguero G, Akin E, Templin C, Kotlarz D, Doerries C, Landmesser U, Grote K, Schieffer B. Renovascular hypertension by two-kidney one-clip enhances endothelial progenitor cell mobilization in a p47phox-dependent manner. J Hypertens. 2008;26(2):257-68.

12. Higgins JP, Thompson SG, Deeks JJ, Altman DG. Measuring inconsistency in meta-analyses. BMJ (Clin Res Ed). 2003;327(7414):557-60.

13. Cumpston M, LiT, Page MJ, Chandler J, Welch VA, Higgins JP, Thomas J. Updated guidance for trusted systematic reviews: a new edition of the Cochrane Handbook for Systematic Reviews of Interventions. Cochrane Database Syst Rev. 2019;10:142.

14. O'Brien PC, Fleming TR. A multiple testing procedure for clinical trials. Biometrics. 1979;35(3):549-56.

15. Suzumura EA, Figueiro M, Normilio-Silva K, Laranjeira L, Oliveira C, Buehler AM, Bugano D, Passos Amato MB, Ribeiro Carvalho CR, Berwanger O, et al. Effects of alveolar recruitment maneuvers on clinical outcomes in patients with acute respiratory distress syndrome: a systematic review and meta-analysis. Intensive Care Med. 2014;40(9):1227-40.

16. Bouman CS, Oudemans-Van Straaten HM, Tijssen JG, Zandstra DF, Kesecioglu J. Effects of early high-volume continuous venovenous hemofiltration on survival and recovery of renal function in intensive care patients with acute renal failure: a prospective, randomized trial. Crit Care Med. 2002;30(10):2205-11.

17. Sugahara S, Suzuki H. Early start on continuous hemodialysis therapy improves survival rate in patients with acute renal failure following coronary bypass surgery. Hemodial Int. 2004;8(4):320-5.

18. Wald R, Adhikari NK, Smith OM, Weir MA, Pope K, Cohen A, Thorpe K, Mclntyre L, Lamontagne F, Soth $\mathrm{M}$, et al. Comparison of standard and accelerated initiation of renal replacement therapy in acute kidney injury. Kidney Int. 2015;88(4):897-904.

19. Zarbock A, Kellum JA, Schmidt C, Van Aken H, Wempe C, Pavenstadt $H$, Boanta A, Gerss J, Meersch M. Effect of early vs delayed initiation of renal replacement therapy on mortality in critically ill patients 
with acute kidney injury: the ELAIN randomized clinical trial. JAMA. 2016;315(20):2190-9.

20. Srisawat N, Laoveeravat P, Limphunudom P, Lumlertgul N, Peerapornratana S, Tiranathanagul K, Susantitaphong P, Praditpornsilpa K, Tungsanga K, Eiam-Ong S. The effect of early renal replacement therapy guided by plasma neutrophil gelatinase associated lipocalin on outcome of acute kidney injury: a feasibility study. J Crit Care. 2018;43:36-41.

21. Lumlertgul N, Peerapornratana S, Trakarnvanich T, Pongsittisak W, Surasit K, Chuasuwan A, Tankee P, Tiranathanagul K, Praditpornsilpa K, Tungsanga $K$, et al. Early versus standard initiation of renal replacement therapy in furosemide stress test non-responsive acute kidney injury patients (the FST trial). Crit Care. 2018;22(1):101.

22. Yang $T$, Zhou $R$, Yao H, Peng L. Effect of timing of continuous renal replacement therapy on prognosis of sepsis patients with acute renal injury. Mod Instrum Med Treat. 2019;25(5):11-5.

23. Bell M. Swing, Granath F, Schon S, Ekbom A, Martling CR: Continuous renal replacement therapy is associated with less chronic renal failure than intermittent haemodialysis after acute renal failure. Intensive Care Med. 2007;33(5):773-80.

24. Lin YF, Ko WJ, Chu TS, Chen YS, Wu VC, Chen YM, Wu MS, Chen YW, Tsai CW, Shiao CC, et al. The 90-day mortality and the subsequent renal recovery in critically ill surgical patients requiring acute renal replacement therapy. Am J Surg. 2009;198(3):325-32.

25. Douvris A, Zeid K, Hiremath S, Bagshaw SM, Wald R, Beaubien-Souligny W, Kong J, Ronco C, Clark EG. Mechanisms for hemodynamic instability related to renal replacement therapy: a narrative review. Intensive Care Med. 2019;45:1333-46.

26. Jaber S, Paugam C, Futier E, Lefrant JY, Lasocki S, Lescot T, Pottecher J, Demoule A, Ferrandiere M, Asehnoune K, et al. Sodium bicarbonate therapy for patients with severe metabolic acidaemia in the intensive care unit (BICAR-ICU): a multicentre, open-label, randomised controlled, phase 3 trial. Lancet. 2018;392(10141):31-40.

27. Gaudry S, Quenot J-P, Hertig A, Barbar SD, Hajage D, Ricard J-D, Dreyfuss D. Timing of renal replacement therapy for severe acute kidney injury in critically ill patients. Am J Respir Crit Care Med. 2019;199(9):1066-75.

28. Karvellas CJ, Farhat MR, Sajjad I, Mogensen SS, Leung AA, Wald R, Bagshaw SM. A comparison of early versus late initiation of renal replacement therapy in critically ill patients with acute kidney injury: a systematic review and meta-analysis. Crit Care. 2011;15(1):R72.

29. Seabra VF, Balk EM, Liangos O, Sosa MA, Cendoroglo M, Jaber BL. Timing of renal replacement therapy initiation in acute renal failure: a metaanalysis. Am J Kidney Dis. 2008;52(2):272-84.

30. Wierstra BT, Kadri S, Alomar S, Burbano X, Barrisford GW, Kao RL. The impact of "early" versus "late" initiation of renal replacement therapy in critical care patients with acute kidney injury: a systematic review and evidence synthesis. Crit Care (Lond, Engl). 2016;20(1):122.

31. Liu Y, Davari-Farid S, Arora P, Porhomayon J, Nader ND. Early versus late initiation of renal replacement therapy in critically ill patients with acute kidney injury after cardiac surgery: a systematic review and meta-analysis. J Cardiothorac Vasc Anesth. 2014;28(3):557-63.

32. Guyatt GH, Oxman AD, Kunz R, Woodcock J, Brozek J, Helfand M, Alonso-Coello P, Glasziou P, Jaeschke R, Akl EA, et al. GRADE guidelines: 7. Rating the quality of evidence-inconsistency. J Clin Epidemiol. 2011;64(12):1294-302.

\section{Publisher's Note}

Springer Nature remains neutral with regard to jurisdictional claims in published maps and institutional affiliations.
Ready to submit your research? Choose BMC and benefit from:

- fast, convenient online submission

- thorough peer review by experienced researchers in your field

- rapid publication on acceptance

- support for research data, including large and complex data types

- gold Open Access which fosters wider collaboration and increased citations

- maximum visibility for your research: over 100M website views per year

At BMC, research is always in progress.

Learn more biomedcentral.com/submissions 